\title{
Doğu Karadeniz Bölgesi kivi bahçelerindeki yabancı ot türleri, rastlama sıklıkları ve genel kaplama alanlarının belirlenmesi*
}

\author{
Arzu SEZER i 1, Onur KOLÖREN ${ }^{1} 1$ \\ ${ }^{1}$ Ordu Üniversitesi, Ziraat Fakültesi, Bitki Koruma Bölümü, Ordu \\ * “Doğu Karadeniz Bölgesi Kivi Bahçelerinde Hastalık Zararlı ve Yabancı Otların Tespiti ile Doğal Düşmanların Belirlenmesi” [Proje No: \\ TAGEM-BS-13/08-09/01-22 (3)] isimli projenin bir bölümüne ait sonuçları içermektedir. "International Ecology 2018 Symposium, 19- \\ 23 June 2018 (Kastamonu, TURKEY)'de sözlü bildiri olarak sunulmuş ve özeti sempozyum özet kitabında yayınlanmıştır.
}

Alınıș tarihi: 30 Temmuz 2019, Kabul tarihi: 2 Aralık 2019

Sorumlu yazar: Arzu SEZER, e-posta: arzusezer@odu.edu.tr

$\ddot{0} \mathbf{z}$

Çalışma 2014-2015 yıllarında Doğu Karadeniz Bölgesi'ndeki kivi bahçelerindeki yabancı ot türleri, rastlama sıklıkları ve genel kaplama alanlarını belirlemek amacıyla yürütülmüştür. Sürvey çalışmaları aynı bahçelerde iki yıl üst üste olmak üzere Giresun, Trabzon, Rize ve Artvin illerindeki 22 kivi bahçesinde Mayıs-Haziran aylarında gerçekleştirilmiştir. Örneklemeler $0.25 \quad \mathrm{~m}^{2}$ 'lik çerçeveler bahçe alanına göre 8-12 kez kullanılarak yapılmıştır. Toplam 27 familyaya ait 49 yabancı ot türü tespit edilmiștir. Poaceae, Asteraceae ve Polygonaceae en fazla tür içeren familyalardır. Giresun'da Conyza canadensis (2014 yılında \%75.00, 2015 yılında \%87.50) Oplismenus undulatifolius (2014 yılında \%75.00, 2015 yılında \%100.00) ve Poa annua (her iki yılda da \%75.00); Trabzon'da, Aethusa cynapium ve 0 . undulatifolius (her iki yılda iki tür de \%66.67); Rize'de O. undulatifolius (2014 yılında $\% 80.00,2015$ yılında \%100.00) ve Artemisia vulgaris (2014 yllında \%60.00, 2015 yilında \%100.00); Artvin'de ise A. vulgaris, Commelina communis, Fragaria vesca ve Poa compressa (her iki yılda da tüm türler \%100.00) en sik rastlanan türler olarak belirlenmiștir. P. annua (2014 yllında \%15.13, 2015 yılında \%14.38) Giresun'da; O. undulatifolius (her iki yılda da \%21.67) ve $P$. compressa (2014 yılında \%14.17, 2015 yılında \%19.17) Trabzon'da, A. vulgaris (2014 yılında \%24.00, 2015 yılında \%26.00) Rize'de; P. compressa (her iki yılda da \%20.00) ise
Artvin'de Genel Kaplama Alanı değeri açısından ilk sıralarda yer almışlardır.

Anahtar kelimeler: Kivi, yabancı ot, Oplismenus undulatifolius, Commelina communis, Poa spp., Artemisia vulgaris

Determination of weed species, their frequency and general coverage areas in kiwifruit orchards in Eastern Black Sea Region of Turkey

\begin{abstract}
This study was carried out to determine weed species, their frequencies and general coverage areas in kiwifruit orchards in Eastern Black Sea Region of Turkey in 2014-2015. Survey studies were conducted in 22 kiwifruit orchards, (same orchards for two consecutive years) located in Giresun, Trabzon, Rize and Artvin provinces on May-June. For sampling, the $0.25 \mathrm{~m}^{2}$ frame was thrown 8-12 times depending on field size. Forty-nine weed species belonging to 27 families were determined. Poaceae, Asteraceae and Polygonaceae were the largest families. Conyza canadensis $75.00 \%$ in 2014 , $87.50 \%$ in 2015$)$, Oplismenus undulatifolius $(75.00 \%$ in 2014, $100.00 \%$ in 2015) and Poa annua $(75.00 \%$ in both years) in Giresun, Aethusa cynapium and $O$. undulatifolius $(66.67 \%$ in 2014 and 2015 for both two species) in Trabzon, 0 . undulatifolius $(80.00 \%$ in $2014,100.00 \%$ in 2015) and Artemisia vulgaris $(60.00 \%$ in $2014,100.00 \%$ in 2015$)$ in Rize, and $A$.
\end{abstract}


vulgaris, Commelina communis, Fragaria vesca and $P$. compressa (100.00\% for all 4 species) in Artvin were the most frequent weeds observed. P. annua (15.13\% in 2014, $14.38 \%$ in 2015) in Giresun, $O$. undulatifolius $(21.67 \%$ in both years) and $P$. compressa (14.17\% in 2014, $19.17 \%$ in 2015) in Trabzon, A. vulgaris $(24.00 \%$ in $2014,26.00 \%$ in $2015)$ in Rize, and P. compressa $(20.00 \%$ in both years) in Artvin took first place in terms of general coverage areas of weeds.

Key words: Kiwifruit, weed, Oplismenus undulatifolius, Commelina communis, Poa spp., Artemisia vulgaris

\section{Giriş}

Anavatanı Çin olan kivi (Actinidia deliciosa (A. Chev.) C.F. Liang \& A.R. Ferguson) dünya çapında ekonomik öneme sahip bir ürün olup, 1900'lü yılların başlarında Yeni Zelanda'da, 1960'larda ise Avrupa'da üretimine başlanmış, tat ve bileşiminde bulunan bazı biyoaktif bileşikler sayesinde tüm dünyada bilinir bir duruma gelmiştir (Atak, 2015; Atak ve ark., 2015; Guroo et al., 2017). 2017 yılı verilerine göre dünyada kivi üretimi 247793 hektar alanda 4038872 ton olarak gerçekleşmiş olup, Çin 2024604 ton üretim ile en büyük kivi üreticisi ülkedir ve onu İtalya ile Yeni Zelanda takip etmektedir (FAO, 2019). Türkiye'de ise kivi üretim çalışmalarına 1988 yılında Yalova'da bulunan Atatürk Bahçe Kültürleri Merkez Araştırma Enstitüsü tarafından başlanmıştır. Yapılan bu çalışmalar sonucu Karadeniz ve Marmara sahil bölgelerinin kivi yetiştiriciliğine uygun olduğu saptanmıştır (Öztürk ve ark., 2012; Atak, 2015). Daha sonra Ülkemizde kivi üretim alanları ve üretim miktarı hızla artış göstermiştir ve 2017 yılı verilerine göre 27435 da alanda toplam 56164 ton üretim yapılmaktadır ve bu değerler ile Ülkemiz dünyada 8 . sırada yer almaktadır (FAO, 2019). Türkiye'de 2018 yılı verilerine göre 25 ilde kivi üretimi yapılmakta ancak üretimin yarıya yakını 25009 ton ile Yalova'da gerçekleşmektedir. Yalova'yı 7336 ton ile Ordu ve 5286 ton ile Rize illeri takip etmektedir. Türkiye kivi üretiminin yaklaşık \%16'sı Doğu Karadeniz Bölgesi'nde Giresun (2204 ton), Trabzon (1955 ton), Rize (5286 ton) ve Artvin (498 ton) illerinde gerçekleşmektedir (TÜİK, 2019). Kivi üretimi açısından önemli bir yere sahip olan bu illerdeki bazı bahçelerde, kivi başta çay olmak üzere diğer bazı bitkilerle birlikte (lahana, fasulye, marul gibi) yetiştirilmektedir. $\mathrm{Bu}$ yetiştiricilikle ilgili resmi istatistiki veriler olmamakla birlikte, gözlemsel olarak Rize ili kivi üretim alanlarının neredeyse yarıya yakınında kivinin çay ile birlikte yetiştirildiği görülmektedir (Sezer ve Kolören, 2018). Türkiye'de birim alandan elde edilen kivi miktarı dünya ortalaması civarında olsa bile bazı ülkelerde bu değer ülkemizin yaklaşık iki katı civarındadır (FAO, 2019). Kivi üretimi açısından uygun bir ekolojiye sahip olan ülkemizde verim ve kaliteyi artırıcı çalışmaların yapılması önemli bir konu olup, öncelikle de verim ve kaliteyi sınırlayan faktörlerin belirlenmesi gerekmektedir.

Yabancı otlar kültür bitkileri ile bașta su, ışık ve mineral maddeler yönünden kuvvetli rekabete girmekte ve bunun sonucu olarak da kültür bitkilerinin veriminde azalmalar ortaya çıkmaktadır. Ayrıca bazı yabancı otlar çıkardıkları birtakım salgılarla kültür bitkilerinin gelişmelerini engellerken, bazıları kültür bitkilerinde zararlı olan hastalık ve zararlıları hem üzerinde barındırarak hem de yıldan yıla geçişine olanak sağlayarak zararlı olmaktadır (Güncan, 2016). Benzer şekilde yabancı otlar kivide de su, besin maddesi ve alan yönünden rekabete girerek hem bitki gelişimini hem de verimini azaltabilir. Anonymous (2013)'e göre optimum kivi meyve üretimi ve omcanın sağlıklı yetişebilmesi için özellikle kivinin taban kısmı etrafındaki yabancı otların mücadelesi gerekli olup, genellikle omcanın etrafindaki yabancı otsuz alan ne kadar geniş olursa omca gelişimi de o kadar fazla olmaktadır ve ayrıca ilk dört yıl kivi ömründe en kritik dönem olup, dördüncü yıl civarında omcalar iyice geliştiğinden ve yabancı otlar üzerinde gölgeleme oluşturduğundan yabancı otların rekabet gücü azalmaktadır. Yabancı otlar genç kivi omcalarıyla oldukça rekabet halinde olduklarından, ilk kurulum aşamalarında dikkatlice mücadele edilmelidir (Anonymous, 2003).

Ülkemizde bitki sağlığı çalışmaları 5996 sayılı Veteriner Hizmetleri, Bitki Sağlı̆̆ı, Gıda ve Yem Kanunu ve hazırlanmış olan ikincil mevzuat ve zirai mücadele teknik talimatları çerçevesinde yürütülmekte olup, henüz kivi üretim alanlarındaki yabancı otlar ve mücadelesi ile ilgili bir teknik talimat mevcut değildir. Ancak Kanyaş (Sorghum halepense), Kırmızı köklü tilkikuyruğu (Amaranthus retroflexus) ve Köpek üzümü (Solanum nigrum) mücadelesi için son dönemde bazı bitki koruma ürünlerinin kullanımı için geçici tavsiye yapıldığı görülmektedir (Anonim, 2019).

Kivinin Ülkemiz açısından nispeten yeni bir ürün olması nedeniyle yabancı otlarının tespiti ve 
mücadelesine yönelik çok fazla literatüre rastlanmamıștır. Ülkemizde kivi üretim alanlarındaki hastalık, zararlı ve yabancl otlar ile doğal düşmanlarının belirlenmesi amacıyla "Ülkesel Kivi Entegre Mücadele Projesi” kapsamında 2014 yılından itibaren Marmara Bölgesi, Orta Karadeniz, Batı Karadeniz ve Doğu Karadeniz Bölgeleri için oluşturulan alt projelerle çalışmalara başlanmıştır (Anonim, 2013). Bu proje kapsamında yürütülen ve Rize ilinde kivi ile çayın beraber yetiştirildiği bahçelerdeki yabancı ot türleri ile ilgili olarak incelenen 15 bahçede 8 familyaya ait 12 yabancl ot türü tespit edilmiştir. Polygonaceae 3 tür ile en fazla tür içeren familya olurken Asteraceae ve Commelinaceae familyalarında ikişer, diğerlerinde ise birer tür yer almıştır. Rastlama Sıklığı en fazla olan türler Oplismenus undulatifolius (\%60), Commelina communis (\%53.33) ve Polygonum convolvulus (\%40) olarak belirlenmiştir. Genel Kaplama Alanı (\%) açısından da O. undulatifolius (\%5.13) ve C. communis (\%4.13) sirasiyla birinci ve ikinci sırada yer almıştır. Bunları \%2.67 ile Tradescantia fluminensis ve \%1.93 ile P. convolvulus izlemiştir (Sezer ve Kolören, 2018).

Ordu ili kivi bahçelerinde yürütülen ve yabancı otların belirlenmesi üzerine yapılan bir çalışmada 32 familyanın 89 cinsine ait tür, alttür ve varyete seviyesinde toplam olarak 110 takson tespit edilmiştir. $\mathrm{Bu}$ bitki taksonlarından çoğunluğunun Poaceae (\%18.18), Asteraceae (\%16.36), Lamiaceae (\% 10.91), Polygonaceae (\%5.45), Fabaceae (\%4.55), Rosaceae (\%4.55), Apiaceae (\%4.55) ve Scrophulariaceae (\%2.70) familyalarına ait oldukları belirlenmiştir (Deveci, 2003). Ordu'da 2015 yılında Yonat ve Kolören (2017)'in iki ayrı dönemde yaptıkları bir çalışmada ise, 26 kivi bahçesinde 33 familyaya ait 86 yabancı ot türü tespit edilmiş olup, genel yabancı otlanma (\%) birinci dönemde (NisanMayıs) \%82.27, ikinci dönemde (Eylül-Ekim) ise \%80.12 olarak bulunmuştur. Bulunan familyalar içerisinde en geniş familya 18 tür ile Asteraceae familyası olmuştur.

Orta Karadeniz Bölgesinde kivi bahçelerinde örtücü bitkilerin kullanım olanaklarının araştırıldığı bir çalışmada, örtücü bitkiler olarak Trifolium repens, Festuca rubra rubra, Festuca arundinacea, Vicia villosa ve Trifolium meneghinianum kullanılmış ve denemede en düşük kivi ürünü yabancı otlu kontrol grubundan elde edilirken en yüksek ürün $F$. arundinacea içeren parsellerden elde edilmiş olup, sonuçlar örtücü bitkilerin kivi bahçelerinde yabancı ot kontrolünde canlı malç olarak kullanılabileceğini göstermiştir (Işık ve ark., 2013a).

$\mathrm{Bu}$ çalışma, Doğu Karadeniz Bölgesinde sadece kivi yetiştiriciliğinin yapıldığı bahçelerdeki yabancı ot türleri, Genel Kaplama Alanları (\%) ve Rastlama Sıklıklarını (\%) belirlemek amaciyla Giresun, Trabzon, Rize ve Artvin illerinde yürütülmüştür.

\section{Materyal ve Yöntem}

Çalışmanın ana materyalini Giresun, Trabzon, Rize ve Artvin illerinde sadece kivi yetiștiriciliği yapılan 22 adet bahçe (Giresun'da 8, Trabzon'da 6, Rize'de 5 ve Artvin'de 3 adet) ve bu bahçelerde saptanan yabancı otlar oluşturmuştur. $0.25 \mathrm{~m}^{2}$ 'lik çerçeve, herbaryum örneği almak ve hazırlamak amaciyla kullanılan presler, kese kağıtları, kurutma kağıtları vb. diğer materyalleri oluşturmuştur.

2014 ve 2015 yıllarında her yıl aynı bahçelerde olmak üzere toplam 22 bahçede sürvey çalışması yapılmış olup, bahçelere ait bilgiler Çizelge 1'de verilmiştir. $\mathrm{Bu}$ bahçeler sadece kivi yetiştiriciliği yapılan bahçeler olup, kivi ile çayın veya sebzelerin birlikte yetiştirildiği bahçeler dikkate alınmamıştır.

Önemli yabancı otlar ve bunların rastlama sıklıkları ve kaplama alanlarını belirlemek amacıyla yürütülen sürvey çalıșması, kivi bahçelerinde görülen yabancı otların kolay tanımlanabileceği Mayıs-Haziran aylarında yapılmıştır. Kivi bahçesi alanının genelini temsil edecek şekilde 1 dekarlık bahçelerde $8 \mathrm{kez}$ (örnekleme alanı olarak minimum 1 dekar alan incelenmiştir), 1 dekardan fazla olan bahçelerde ise $12 \mathrm{kez} 50 \mathrm{~cm} \quad \mathrm{x} 50 \quad \mathrm{~cm}=0.25 \quad \mathrm{~m}^{2}$ lik çerçeve kullanılarak yabancı otların türleri ve kapladıkları alanlar kaydedilmiştir. Daha sonra yabancl ot türlerinin örnekleme alanındaki Genel Kaplama Alanı (\%) ve Rastlama Sıklığı (\%) aşağıdaki formüllere göre hesaplanmıştır (Odum, 1971).

Rastlama sıklığı (\%) : n/m x 100

Genel Kaplama Alanı (\%) : T.K.A./m

n: Türün rastlanıldığı bahçe sayısı

m: Örnekleme yapılan toplam bahçe sayısı

T.K.A.: Her türün \% kaplama alanlarının toplamı

Yabancı ot türlerinin teşhisinde kaynak olarak Flora of Turkey (Davis, 1965-1988) ve Ackerunkraeuter Europas (Hanf, 1990) kullanılmıştır. Yabancı otların Türkçe isimleri Tazegül (1988), Uluğ ve ark. (1993) ve Güner ve ark. (2012)'na göre alınmıştır. 
Çizelge 1. Sürvey yapılan bahçelerin lokasyon ve alanları

\begin{tabular}{|c|c|c|c|}
\hline İl & İlçe & Mahalle/Köy & $\begin{array}{l}\text { Alan } \\
\text { (da) }\end{array}$ \\
\hline \multirow{8}{*}{ Giresun } & \multirow{4}{*}{ Merkez } & Merkez-1 & 2 \\
\hline & & Kayadibi Mah. & 6 \\
\hline & & Aydınlar Mah. & 1.5 \\
\hline & & Merkez-2 & 1 \\
\hline & Yağlıdere & Merkez & 1 \\
\hline & \multirow{3}{*}{ Tirebolu } & Örenkaya köyü & 1 \\
\hline & & Merkez & 3 \\
\hline & & Çeğel köyü & 1 \\
\hline \multirow{6}{*}{ Trabzon } & \multirow{2}{*}{ Akçaabat } & Derecik- Merkez & 1.5 \\
\hline & & Derecik- Uğurlu & 1 \\
\hline & \multirow{4}{*}{ Arsin } & Yeşilce-1 & 1.5 \\
\hline & & Yeşilyalı-Yaylacık Mah. & 1 \\
\hline & & Yeșilce-2 & 2 \\
\hline & & Yeșilce-3 & 3 \\
\hline \multirow{5}{*}{ Rize } & Çayeli & Taşhane Mah. & 3 \\
\hline & \multirow{3}{*}{ Ardeşen } & Seslikaya & 1.5 \\
\hline & & Beyazkaya köyü & 4 \\
\hline & & Merkez & 1 \\
\hline & Findıklı & Merkez & 9 \\
\hline \multirow{4}{*}{ Artvin } & \multirow{3}{*}{ Arhavi } & Kavak Mah. & 2 \\
\hline & & Yemişlik Mah. & 1 \\
\hline & & Merkez & 1.5 \\
\hline & \multicolumn{2}{|c|}{ Toplam } & 49.5 \\
\hline
\end{tabular}

\section{Bulgular ve Tartışma}

Doğu Karadeniz Bölgesi'nde Giresun, Trabzon, Rize ve Artvin illeri kivi üretim alanlarında üst üste iki yıl aynı bahçelerde yapılan sürveyler sonucu 4 ilde toplam 27 familyaya ait 49 ayrı yabancl ot belirlenmiştir. Poaceae (8 tür), Asteraceae (5 tür) ve Polygonaceae (5 tür) familyaları en fazla tür içeren familyalar olarak tespit edilmiștir (Şekil 1). Deveci (2003)'ye göre de Ordu ili kivi bahçelerinde en fazla tür içeren familyalar benzer şekilde Poaceae (\%18.18) ve Asteraceae (\%16.36) familyalarıdır. Yonat ve Kolören (2017) de yine Ordu'da Asteraceae familyasını en fazla tür içeren familya olarak tespit etmişlerdir. Yabancı ot türlerinden Conyza canadensis, C. communis, Phytolacca americana, Plantago sp., O. undulatifolius, Polygonum persicaria, Rumex obtusifolius ve Fragaria vesca sürvey yapılan tüm illerde tespit edilmiştir. Stellaria media, Trifolium repens, Lolium perenne, Puccinellia distans sadece Trabzon'da, Trachystemon orientalis, Tradescantia fluminensis, Oxalis acetosella sadece Rize'de, Persicaria perfoliata sadece Artvin'de gözlenirken çok sayıda yabancı ot türü de sadece Giresun'daki kivi üretim alanlarında saptanmıştır (Çizelge 2).

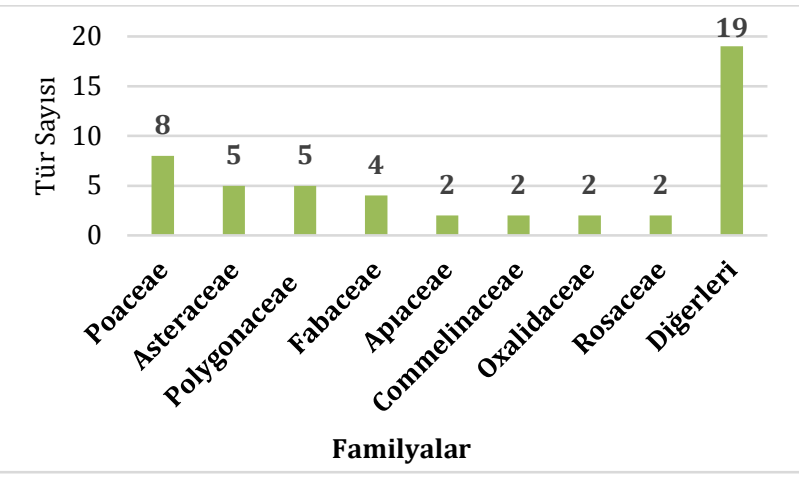

Şekil 1. Sürvey çalışması sonucunda tespit edilen yabancı ot türlerinin familyalara göre dağılımı

Giresun, Trabzon, Rize ve Artvin illeri kapama kivi bahçelerinde tespit edilen yabancı otların Genel Kaplama Alanları (\%) ve Rastlama Sıklıkları (\%) Çizelge 3 - 6'da verilmiștir. Giresun'da 2014 ve 2015 yıllarında genel kaplama alanı en yüksek olan yabancl ot türü Poa annua (\%15.13 ve \%14.38 değerleri ile) olmuştur. Her iki yılda da Aethusa cynapium, Rubus sp., Chenopodium album ve $O$. undulatifolius genel kaplama alanı açısından ilk 5 yabancı ot içinde yer almıştır. Rastlama Sıklığı (\%) açısından ise $C$. canadensis, $O$. undulatifolius ve $P$. annua her iki yılda da en yüksek değere sahip olmuştur. Giresun ile benzer coğrafik koşullara sahip Ordu'da 2015 yılında yapılan çalışmalarda da Poaceae familyasından başka bir tür olan Poa trivialis birinci dönemde en fazla kaplama alanına sahip yabancl ot türü olarak tespit edilmiştir (Yonat ve Kolören, 2017). Trabzon'da O. undulatifolius (\%21.67) ve Poa compressa (\%14.17 ve \%19.17) her iki yılda da kaplama alanı (\%) en yüksek olan yabancı ot türleri olmuş, bunu 2014 yılında $A$. retroflexus, 2015 yılında Arum sp. izlemiştir. Rastlama Sıklığı (\%) en yüksek olan türler ise her iki yllda da $A$. cynapium ve $O$. undulatifolius olmuştur. $A$. retroflexus Yonat ve Kolören (2017)'e göre Ordu'da 2015 yılı ikinci dönemde (Eylül-Ekim) rastlama sıklığı (\%50) en yüksek ikinci tür olarak tespit edilmiştir. O. undulatifolius ise aynı çalışmada aynı dönemde \%38.46 Rastlama Sıklı̆̆ı değeri ile gözlenmiștir. 26.06.2019 tarihinde kivide $A$. retroflexus mücadelesi için Tarım ve Orman Bakanlığı tarafından geçici bitki koruma ürünü tavsiyesi yapılmış olması bu yabancı otun kivideki zararının önemli bir boyuta ulaştığının göstergesidir. 
Çizelge 2. İllere göre kivi bahçelerinde yabancı ot türlerinin bulunma durumu

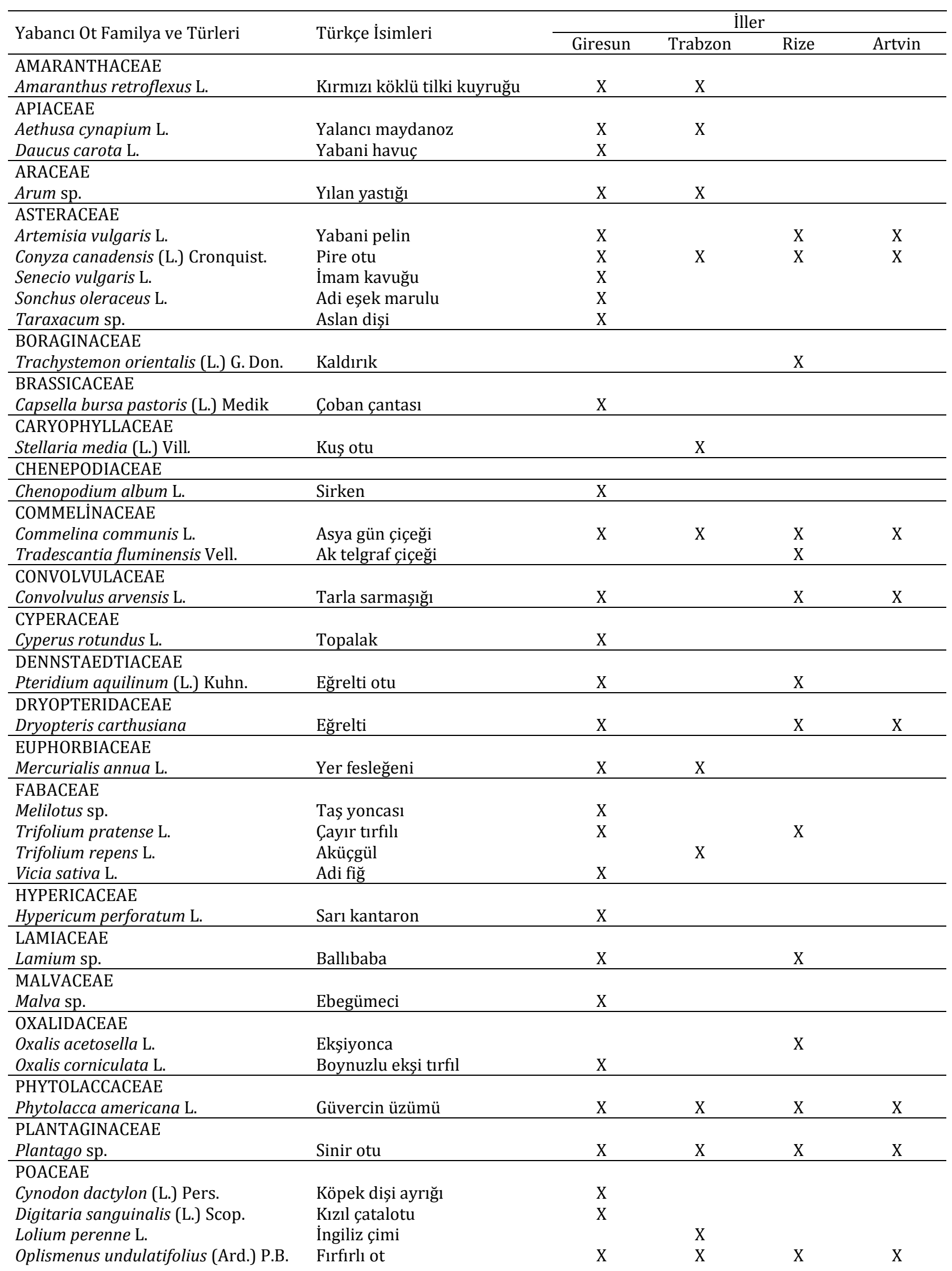


Çizelge 2. İllere göre kivi bahçelerinde yabancı ot türlerinin bulunma durumu (devamı)

\begin{tabular}{|c|c|c|c|c|c|}
\hline \multirow{2}{*}{ Yabancı Ot Familya ve Türleri } & \multirow{2}{*}{ Türkçe İsimleri } & \multicolumn{4}{|c|}{ İller } \\
\hline & & Giresun & Trabzon & Rize & Artvin \\
\hline Poa annua L. & Tek yıllık salkım otu & $\mathrm{X}$ & & & \\
\hline Poa compressa L. & Yassı salkım otu & & $\mathrm{X}$ & & $\mathrm{X}$ \\
\hline Puccinellia distans (Jacq.) Parl. & Çorak çimi & & $\mathrm{X}$ & & \\
\hline Setaria glauca (L.) P.B. & Sarı tüylü darı & $\mathrm{X}$ & & $\mathrm{X}$ & \\
\hline \multicolumn{6}{|l|}{ POLYGONACEAE } \\
\hline Polygonum aviculare $\mathrm{L}$. & Çoban değneği & $\mathrm{X}$ & & & \\
\hline Polygonum convolvulus $\mathrm{L}$. & Sarmașık çoban değneği & & & $\mathrm{X}$ & $\mathrm{X}$ \\
\hline $\begin{array}{l}\begin{array}{l}\text { Persicaria perfoliata (L.) H. } \\
\text { Gross (Syn: Polygonum } \\
\text { perfoliatum L.) }\end{array}\end{array}$ & $\begin{array}{l}\text { Dikenli sarmaşık çoban } \\
\text { değneği }\end{array}$ & & & & $\mathrm{X}$ \\
\hline Polygonum persicaria L. & Kırmızı ayaklı kara buğday & $\mathrm{X}$ & $\mathrm{X}$ & $\mathrm{X}$ & $\mathrm{X}$ \\
\hline Rumex obtusifolius L. & Küt yapraklı labada & $\mathrm{X}$ & $\mathrm{X}$ & $\mathrm{X}$ & $\mathrm{X}$ \\
\hline \multicolumn{6}{|l|}{ ROSACEAE } \\
\hline Fragaria vesca L. & Dağ çileği & $\mathrm{X}$ & $\mathrm{X}$ & $\mathrm{X}$ & $\mathrm{X}$ \\
\hline Rubus sp. & Böğürtlen & $\mathrm{X}$ & & $\mathrm{X}$ & \\
\hline RUBIACEAE & & & & & \\
\hline Galium aparine L. & Dil kanatan & $\mathrm{X}$ & & & \\
\hline \multicolumn{6}{|l|}{ SOLANACEAE } \\
\hline Solanum nigrum L. & Köpek üzümü & $\mathrm{X}$ & $\mathrm{X}$ & & \\
\hline \multicolumn{6}{|l|}{ URTICACEAE } \\
\hline Urtica sp. & Isırgan & $\mathrm{X}$ & & $\mathrm{X}$ & $\mathrm{X}$ \\
\hline
\end{tabular}

Rize'de Artemisia vulgaris her iki yılda da kaplama alanı en yüksek olan tür olurken T. orientalis, $O$. undulatifolius ve P. convolvulus türleri genel kaplama alanı en yüksek diğer türler olmuştur. 2014 yılında O. undulatifolius'un rastlama sıklı̆̆ $\% 80.00, A$. vulgaris ve Dryopteris carthusiana'nınki \%60.00 iken 2018 yılında bu değer O. undulatifolius ve A. vulgaris için \%100.00, D. carthusiana için \%80.00 olmuştur.

Artvin'de incelenen 3 bahçede genel kaplama alanı açısından 2014 yılında $P$. compressa (\%20.00), $O$. undulatifolius (\%18.33) ve P. convolvulus (\%16.67); 2015 yllinda ise $P$. compressa (\%20.00) $P$. convolvulus (\%18.33) ve P. perfoliata (\%13.33) ilk 3 sırada yer almıştır. A. vulgaris, $C$. communis, $F$. vesca ve $P$. compressa her iki yılda da tüm bahçelerde gözlenmiștir. Bunlardan Ülkemiz için istilacı bitkiler içinde yer alan $P$. perfoliata'nın özellikle Karadeniz Bölgesi için önemli bir tehdit olabileceği düşünülmekte ve halihazırda özellikle Doğu Karadeniz Bölgesine yerleşmiş olup çay, fındık ve kivi gibi çok yıllık kültür bitkilerinde, sebze alanlarında, tarla ve bahçe kenarlarında yoğun olarak bulunmaktadır (Önen et al., 2015).

Genel olarak baktığımızda, Doğu Karadeniz Bölgesi kivi üretim alanlarındaki en önemli yabancı otların
O. undulatifolius, C. communis, Poa spp., A. vulgaris ve A. retroflexus olduğu belirlenmiştir. Bunlara karşı uygun metotlar belirlenerek mücadele yapılması gerekmektedir. Bunlardan C. communis (Farooq ve Önen 2015) ve A. vulgaris (Işık ve ark., 2013b) ülkemiz için istilacı türler içinde yer alması nedeniyle daha fazla dikkat gerektirmektedir. Ayrıca tespit edilen türlerden P. perfoliata, T. fluminensis, $C$. canadensis ve $P$. americana, Rubus sp., ve $P$. aquilinum türleri de Türkiye için istilacı bitkiler kategorisinde yer almaktadır (Işık ve ark. 2013b; Akyol ve ark., 2015; Bükün ve Özarslan, 2015; Karaer ve ark., 2015; Önen ve ark., 2015). Bu tür yabancı otlar genel zararları yanında ekosistemin biyotik ve abiyotik çeşitliliğini olumsuz yönde etkilemektedirler (Önen, 2015).

Kivide verim ve kalitenin arttırılması ve ekosistemin korunması açısından hem bölgede sıkça rastlanan istilacı yabancı otların hem de diğer yabancı otların üreticilere tanıtılarak uygun bir şekilde mücadele edilmesi ve yayılmalarının sıkı karantina tedbirleri ile önlenmesi sağlanmalıdır. Bunun için de öncelikli olarak kivideki yabancı otlar ve mücadelesi hakkında zirai mücadele teknik talimatı hazırlanarak teknik elemanlar ve üreticilerin hizmetine sunulmalıdır. 
Çizelge 3. Giresun ili kivi bahçelerinde rastlanan yabancı otların genel kaplama alanları (\%) ve rastlama sıklığı (\%)

\begin{tabular}{|c|c|c|c|c|}
\hline \multirow{2}{*}{ Yabancı Ot Türleri } & \multicolumn{2}{|c|}{2014 Ylll } & \multicolumn{2}{|c|}{2015 Yllı } \\
\hline & GKA (\%)* & RS (\%)** & GKA (\%)* & RS $(\%)^{* *}$ \\
\hline Aethusa cynapium & 12.50 & 37.50 & 10.00 & 37.50 \\
\hline Amaranthus retroflexus & 0.63 & 12.50 & 0.63 & 12.50 \\
\hline Artemisia vulgaris & 5.38 & 50.00 & 5.63 & 50.00 \\
\hline Arum sp. & 0.00 & 0.00 & 0.38 & 25.00 \\
\hline Capsella bursa-pastoris & 0.00 & 0.00 & 1.63 & 37.50 \\
\hline Chenopodium album & 9.13 & 25.00 & 6.25 & 37.50 \\
\hline Commelina communis & 1.25 & 12.50 & 2.50 & 37.50 \\
\hline Convolvulus arvensis & 0.88 & 37.50 & 1.13 & 37.50 \\
\hline Conyza canadensis & 5.38 & 75.00 & 5.38 & 87.50 \\
\hline Cynodon dactylon & 0.00 & 0.00 & 2.50 & 12.50 \\
\hline Cyperus rotundus & 0.00 & 0.00 & 4.38 & 12.50 \\
\hline Daucus carota & 0.00 & 0.00 & 0.13 & 12.50 \\
\hline Digitaria sanguinalis & 0.00 & 0.00 & 0.88 & 25.00 \\
\hline Fragaria vesca & 1.00 & 25.00 & 1.00 & 25.00 \\
\hline Galium aparine & 0.00 & 0.00 & 0.38 & 12.50 \\
\hline Hypericum perforatum & 0.25 & 25.00 & 0.38 & 25.00 \\
\hline Lamium sp. & 0.00 & 0.00 & 0.75 & 37.50 \\
\hline Malva sp. & 0.00 & 0.00 & 0.25 & 12.50 \\
\hline Dryopteris carthusiana & 0.88 & 25.00 & 1.50 & 37.50 \\
\hline Melilotus sp. & 0.75 & 12.50 & 0.75 & 12.50 \\
\hline Mercurialis annua & 0.00 & 0.00 & 2.63 & 25.00 \\
\hline Oplismenus undulatifolius & 7.88 & 75.00 & 8.50 & 100.00 \\
\hline Oxalis corniculata & 0.88 & 25.00 & 0.75 & 25.00 \\
\hline Phytolacca americana & 0.25 & 12.50 & 0.00 & 0.00 \\
\hline Plantago sp. & 0.00 & 0.00 & 0.75 & 37.50 \\
\hline Poa annua & 15.13 & 75.00 & 14.38 & 75.00 \\
\hline Polygonum aviculare & 0.00 & 0.00 & 0.63 & 12.50 \\
\hline Polygonum persicaria & 3.13 & 25.00 & 1.88 & 25.00 \\
\hline Pteridium aquilinum & 0.38 & 12.50 & 0.63 & 12.50 \\
\hline Rubus sp. & 10.63 & 25.00 & 7.50 & 25.00 \\
\hline Rumex obtusifolius & 2.50 & 25.00 & 2.50 & 37.50 \\
\hline Senecio vulgaris & 0.00 & 0.00 & 0.13 & 12.50 \\
\hline Setaria glauca & 3.13 & 25.00 & 4.00 & 50.00 \\
\hline Solanum nigrum & 0.75 & 25.00 & 0.13 & 12.50 \\
\hline Sonchus oleraceus & 0.13 & 12.50 & 0.50 & 25.00 \\
\hline Taraxacum sp. & 0.25 & 12.50 & 0.25 & 12.50 \\
\hline Trifolium pratense & 0.00 & 0.00 & 1.25 & 12.50 \\
\hline Urtica sp. & 1.38 & 37.50 & 3.13 & 75.00 \\
\hline Vicia sativa & 0.00 & 0.00 & 0.38 & 12.50 \\
\hline
\end{tabular}

Çizelge 4. Trabzon ili kivi bahçelerinde rastlanan yabancı otların genel kaplama alanları (\%) ve rastlama slklığı (\%)

\begin{tabular}{|c|c|c|c|c|}
\hline \multirow{2}{*}{ Yabancı Ot Türleri } & \multicolumn{2}{|c|}{2014 Yilı } & \multicolumn{2}{|c|}{2015 Yilı } \\
\hline & GKA (\%)* & RS $(\%)^{* *}$ & GKA (\%)* & RS $(\%)^{* *}$ \\
\hline Aethusa cynapium & 3.33 & 66.67 & 3.33 & 66.67 \\
\hline Amaranthus retroflexus & 13.33 & 16.67 & 0.83 & 16.67 \\
\hline Arum sp. & 0.00 & 0.00 & 12.50 & 16.67 \\
\hline Commelina communis & 3.33 & 50.00 & 3.33 & 50.00 \\
\hline Conyza canadensis & 2.50 & 50.00 & 3.33 & 66.67 \\
\hline Fragaria vesca & 0.50 & 16.67 & 1.17 & 33.33 \\
\hline Lolium perenne & 0.83 & 16.67 & 0.83 & 16.67 \\
\hline Mercurialis annua & 0.83 & 16.67 & 0.83 & 16.67 \\
\hline Oplismenus undulatifolius & 21.67 & 66.67 & 21.67 & 66.67 \\
\hline Phytolacca americana & 0.00 & 0.00 & 0.17 & 16.67 \\
\hline Plantago sp. & 0.83 & 16.67 & 1.17 & 33.33 \\
\hline Poa compressa & 14.17 & 33.33 & 19.17 & 33.33 \\
\hline Polygonum persicaria & 0.83 & 16.67 & 0.83 & 16.67 \\
\hline Puccinellia distans & 0.00 & 0.00 & 1.67 & 16.67 \\
\hline Rumex obtusifolius & 0.83 & 16.67 & 0.83 & 16.67 \\
\hline Solanum nigrum & 0.83 & 16.67 & 0.83 & 16.67 \\
\hline Stellaria media & 0.00 & 0.00 & 0.83 & 16.67 \\
\hline Trifolium repens & 1.17 & 33.33 & 1.67 & 33.33 \\
\hline
\end{tabular}


Çizelge 5. Rize ili kivi bahçelerinde rastlanan yabancı otların genel kaplama alanları (\%) ve rastlama sıklığı $(\%)$

\begin{tabular}{|c|c|c|c|c|}
\hline \multirow{2}{*}{ Yabancı Ot Türleri } & \multicolumn{2}{|c|}{2014 Yllı } & \multicolumn{2}{|c|}{2015 Yilı } \\
\hline & GKA (\%)* & $\mathrm{RS}(\%)^{* *}$ & GKA $(\%)^{*}$ & $\mathrm{RS}(\%)^{* *}$ \\
\hline Artemisia vulgaris & 24.00 & 60.00 & 26.00 & 100.00 \\
\hline Commelina communis & 0.00 & 0.00 & 1.00 & 20.00 \\
\hline Convolvulus arvensis & 0.00 & 0.00 & 1.40 & 40.00 \\
\hline Conyza canadensis & 0.00 & 0.00 & 0.20 & 20.00 \\
\hline Fragaria vesca & 2.00 & 20.00 & 2.60 & 40.00 \\
\hline Lamium sp. & 1.00 & 20.00 & 1.00 & 20.00 \\
\hline Dryopteris carthusiana & 7.00 & 60.00 & 7.40 & 80.00 \\
\hline Oplismenus undulatifolius & 9.00 & 80.00 & 11.00 & 100.00 \\
\hline Oxalis acetosella & 2.40 & 40.00 & 2.40 & 40.00 \\
\hline Phytolacca americana & 1.00 & 20.00 & 1.00 & 20.00 \\
\hline Plantago sp. & 0.00 & 0.00 & 0.20 & 20.00 \\
\hline Polygonum convolvulus & 8.00 & 40.00 & 10.00 & 60.00 \\
\hline Polygonum persicaria & 1.00 & 20.00 & 3.00 & 40.00 \\
\hline Pteridium aquilinum & 1.00 & 20.00 & 1.00 & 20.00 \\
\hline Rubus sp. & 8.00 & 20.00 & 4.00 & 20.00 \\
\hline Rumex obtusifolius & 1.00 & 20.00 & 5.00 & 40.00 \\
\hline Setaria glauca & 4.00 & 20.00 & 2.00 & 20.00 \\
\hline Trachystemon orientalis & 12.00 & 20.00 & 8.00 & 20.00 \\
\hline Tradescantia fluminensis & 6.00 & 20.00 & 6.00 & 20.00 \\
\hline Trifolium pratense & 0.00 & 0.00 & 0.40 & 20.00 \\
\hline Urtica sp. & 2.00 & 20.00 & 2.00 & 20.00 \\
\hline
\end{tabular}

*GKA: Genel Kaplama Alanı, **RS: Rastlama Sıklığı

Çizelge 6. Artvin ili kivi bahçelerinde rastlanan yabancı otların genel kaplama alanları (\%) ve rastlama sıklı̆̆ı $(\%)$

\begin{tabular}{|c|c|c|c|c|}
\hline \multirow{2}{*}{ Yabancı Ot Türleri } & \multicolumn{2}{|c|}{2014 Yllı } & \multicolumn{2}{|c|}{2015 Yilı } \\
\hline & GKA (\%)* & RS $(\%)^{* *}$ & GKA (\%)* & RS (\%)** \\
\hline Artemisia vulgaris & 10.00 & 100.00 & 11.67 & 100.00 \\
\hline Commelina communis & 5.00 & 100.00 & 6.67 & 100.00 \\
\hline Convolvulus arvensis & 1.67 & 33.33 & 1.67 & 33.33 \\
\hline Conyza canadensis & 1.67 & 33.33 & 1.67 & 33.33 \\
\hline Fragaria vesca & 10.00 & 100.00 & 6.67 & 100.00 \\
\hline Dryopteris carthusiana & 1.67 & 33.33 & 1.67 & 33.33 \\
\hline Oplismenus undulatifolius & 18.33 & 33.33 & 10.00 & 33.33 \\
\hline Persicaria perfoliata & 0.33 & 33.33 & 13.33 & 66.67 \\
\hline Phytolacca americana & 0.33 & 33.33 & 0.33 & 33.33 \\
\hline Plantago sp. & 1.67 & 33.33 & 1.67 & 33.33 \\
\hline Poa compressa & 20.00 & 100.00 & 20.00 & 100.00 \\
\hline Polygonum convolvulus & 16.67 & 66.67 & 18.33 & 66.67 \\
\hline Polygonum persicaria & 1.67 & 33.33 & 1.67 & 33.33 \\
\hline Rumex obtusifolius & 2.67 & 66.67 & 3.00 & 100.00 \\
\hline Urtica sp. & 1.33 & 66.67 & 1.67 & 66.67 \\
\hline
\end{tabular}

*GKA: Genel Kaplama Alanı, ${ }^{* *}$ RS: Rastlama Sıklığı

\section{Teşekkür}

$\mathrm{Bu}$ çalıșma Tarımsal Araștırmalar ve Politikalar Genel Müdürlüğü tarafından desteklenmiştir [Proje No: TAGEM-BS-13/08-09/01-22 (3)] Projenin hazırlanmasındaki katkılarından dolayı Nagehan ÇİL TURGUT (Karadeniz Tarımsal Araştırma Enstitüsü)'a teşekkür ederiz.

\section{Kaynaklar}

Akyol, N., Önen, H., Sarı, T., 2015. "Phytolacca americana, 441-449”. Türkiye İstilacı Bitkiler Kataloğu (Ed. H. Önen). Ezgi Ofset Matbaacılık, Ankara, 533 s.

Anonim, 2013. https://www.tarimorman.gov.tr/TAGEM/ Menu/27/Proje-Degerlendirme-Toplantilari (Eri şim tarihi: 25.07.2019). 
Anonim, 2019. https://bku.tarim.gov.tr/ (Erişim tarihi: 25.07.2019).

Anonymous, 2003. A pest management strategic plan for kiwifruit production in California. https://ipmdata.ipmcenters.org/documents/pmsp s/CAKIWIFRUIT.PDF (Erişim tarihi: 25.07.2019).

Anonymous, 2013. Kiwifruit. Agricultural pest management. Integrated weed management. http://ipm.ucanr.edu/PMG/r430700111.html (Erişim tarihi: 25.07.2019).

Atak, A., 2015. Kiwifruit research and production in Turkey. Acta Horticulturae, 1096: 63-67.

Atak, A., Ferguson A.R., Testolin R., 2015. Türkiye ve dünya kivi yetiştiriciliğinin karşılaştırılması. Selçuk Tarım Bilimleri Dergisi, 8. Bağcılık ve Teknolojileri Sempozyumu Özel Sayısı, 27(3): 721-732.

Bükün, B., Özarslan, C., 2015. “Conyza canadensis, 261264". Türkiye İstilacı Bitkiler Kataloğu (Ed. H. Önen). Ezgi Ofset Matbaacılık, Ankara, 533 s.

Davis, P.H., 1965-1988. Flora of Turkey and the East Aegean Islands. Volume 1-10. University Press, Edingburg.

Deveci, M., 2003. Ordu ili kivi bahçelerinde bulunan bitkiler, bunların yoğunlukları ve rastlama sıklıklarının belirlenmesi. Karadeniz Teknik Üniversitesi, Ordu Ziraat Fakültesi, Ulusal Kivi ve Üzümsü Meyveler Sempozyumu (23-25 Ekim 2003, Ordu) Bildirileri, 197-202 s.

FAO, 2019. http://www.fao.org/faostat/en/\#data/QC (Erişim tarihi: 25.07.2019).

Farooq, S., Önen H., 2015. "Commeline communis. 239-247”. Türkiye İstilacı Bitkiler Kataloğu (Ed. H. Önen). Ezgi Ofset Matbaacılık, Ankara, 533 s.

Guroo, I., Wani, S.A., Wani, S.M., Ahmad, M., Mir, S.A., Masoodi, F.A., 2017. A Review of production and processing of kiwifruit. Journal of Food Processing and Technology, 8: 699.

Güncan, A. 2016., Yabancı Otlar ve Mücadele Prensipleri. Selçuk Üniversitesi Yayınevi, Konya, 311 s.

Güner, A., Arslan S., Ekim T., Vural M., Babaç, M.T., 2012. Türkiye Bitkiler Listesi (Damarlı Bitkiler). Nezahat Gökyiğit Botanik Bahçesi ve Flora Araştırmaları Derneği Yayını, İstanbul.
Hanf, M., 1990. Ackerunkraeuter Europas. Mit Ihren Keimlingen und Samen, Germany, 496 p.

Işık, D., Dok, M., Ak, K., Macit, İ., Demir, Z., Mennan H. 2013a. Possible use of cover crops in weed control on kiwi orchards in black sea region of Turkey. Book Of Abstracts Of Joint Workshop Of The Ewrs Workıng Groups: Novel And Sustainable Weed Management In Arld And Semi-Arıd Agro Ecosystems And Weed Mapping. (29 September 03 October 2013, Crete, Greece), 45 p.

Işık, D., Gözükara, K., Türkmen, G., Karnas, Z., Bingöl, S., Akça, A., Mennan, H. 2013b. Invasive Weeds in Black Sea Region of Turkey. 4th ESENIAS Workshop: International Workshop on IAS in Agricultural and Non-Agricultural Areas in ESENIAS Region (16-17 December 2013, Çanakkale, Turkey), 72-77 p.

Karaer, F., Kutbay H.G., Terzioğlu S., 2015. “Tradescantia fluminensis, 505-513". Türkiye İstilacı Bitkiler Kataloğu (Ed. H. Önen). Ezgi Ofset Matbaacılık, Ankara, 533 s.

Odum, E.P., 1971. Fundamentals of Ecology. W.B. Saunders Company, Philadelphia, London, Toronto, $574 \mathrm{p}$.

Önen, H., 2015. Türkiye İstilacı Bitkiler Kataloğu. Ezgi Ofset Matbaacllık, Ankara, $532 \mathrm{~s}$.

Önen, H., Özarslan C., and Çaldıran U., 2015. "Persicaria perfoliata, 410-423". Türkiye İstilacı Bitkiler Kataloğu (Ed. H. Önen). Ezgi Ofset Matbaacılık, Ankara, $533 \mathrm{~s}$.

Öztürk, M., Kahraman, K.A., Pezikoğlu, F., 2012. Türkiye'de kivi yetiștiriciliği yapan işletmelerin sosyoekonomik analizi. 10. Ulusal Tarım Ekonomisi Kongresi (5-7 Eylül 2012, Konya), Cilt 1: 551-560.

Sezer, A., Kolören, O., 2018. Weed species in kiwifruit-tea intercropping orchards in Rize province of Turkey. Book of Proceedings the 2nd international UNIDOKAP Black Sea Symposium on Biodıversity, (28-30 November 2018, Samsun, Turkey) Bildirileri: 135-137 p.

Tazegül, E., 1988. Dictionary of Agricultural Sciences (Botany-Forestry-Meteorology). Reform Press, İzmir. Vol 1, $818 \mathrm{p}$.

TÜİK, 2019. www.tuik.gov.tr. https://biruni.tuik.gov.tr/ medas $/$ ?kn=92\&locale=tr (Erişim tarihi: 25.07. 2019). 
Uluğ, E., Kadığlu, İ., Üremiş, İ., 1993. Türkiye'nin Yabancı Otları ve Bazı Özellikleri. T.C. Tarım ve Köyişleri Bakanlı̆̆ı, Zirai Mücadele Araştırma Enstitüsü Müdürlüğü, Yayın No:78, Adana, 513 s.
Yonat, H., Kolören, O., 2017. Determination of weed species in kiwifruit orchards of Ordu province-Turkey. Harran Tarım ve Gıda Bilimleri Dergisi, 21 (2): 155163. 